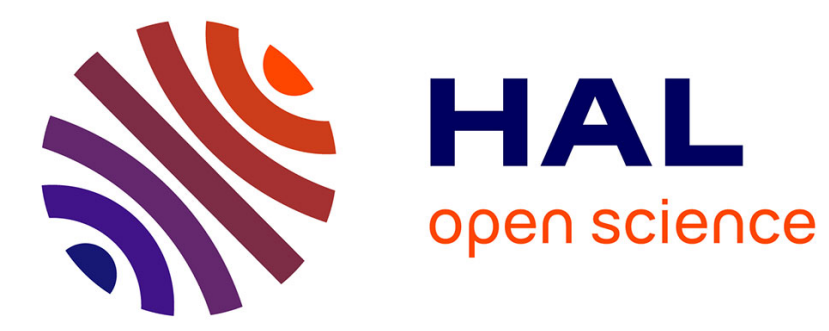

\title{
Decision making during preoperative surgical planning.
}

Thierry Morineau, Xavier Morandi, Nadège Le Moëllic, Sylma Diabira, Laurent Riffaud, Claire Haegelen, Pierre-Louis Hénaux, Pierre Jannin

\section{To cite this version:}

Thierry Morineau, Xavier Morandi, Nadège Le Moëllic, Sylma Diabira, Laurent Riffaud, et al.. Decision making during preoperative surgical planning.: Pre-operative Surgical Planning. Human Factors, 2009, 51 (1), pp.67-77. inserm-00546494

\section{HAL Id: inserm-00546494 https://www.hal.inserm.fr/inserm-00546494}

Submitted on 17 Dec 2010

HAL is a multi-disciplinary open access archive for the deposit and dissemination of scientific research documents, whether they are published or not. The documents may come from teaching and research institutions in France or abroad, or from public or private research centers.
L'archive ouverte pluridisciplinaire HAL, est destinée au dépôt et à la diffusion de documents scientifiques de niveau recherche, publiés ou non, émanant des établissements d'enseignement et de recherche français ou étrangers, des laboratoires publics ou privés. 
Running Head: Pre-operative Surgical Planning

\section{Decision-Making during Pre-operative Surgical Planning}

Authors: Thierry Morineau (1), Xavier Morandi (2, 3, 4, 5), Nadège Le Moëllic (1), Sylma Diabira (2,5), Laurent Riffaud (2, 5), Claire Haegelen (2, 5), Pierre-Louis Hénaux (2, 5), and Pierre Jannin $(2,3,4)$

1. University of Southern Brittany, CRPCC-LESTIC laboratory, Yves Coppens centre, F56000 Vannes, France

2. INSERM, U746, Faculty of Medicine CS 34317, F-35043 Rennes, France

3. INRIA, VisAGeS Unit/Project, F-35042 Rennes, France

4. University of Rennes I, CNRS, UMR 6074, IRISA, F-35042 Rennes, France

5. Department of Neurosurgery, Pontchaillou University Hospital, F-35043 Rennes, France

Section: RESEARCH REPORTS

Corresponding author: Thierry Morineau - Université de Bretagne Sud, LESTIC, Centre Yves Coppens, Campus de Tohannic, F-56000 Vannes, France, thierry.morineau@univ-ubs.fr; Phone: +33 (0)2 970171 37, Fax: +33(0)2 97017071 


\section{Abstract}

Objective: This study concerns the analysis of decision-making during pre-operative surgical planning, and the measure of the impact of expertise and surgical case complexity through the definition of cognitive indicators: conflict and cognitive control. Background: Planning is a critical stage in naturalistic decision-making and there is some evidence suggesting that this activity depends on the level of expertise, and task demands. Cognitive Engineering allows for envisaging surgery as a control task performed by the surgical work system on patient body work domain. The specificity of surgery resides in the necessity to cope with (potential) conflicts between the intervention purposes of the surgical work system, and biological laws governing the patient body. Method: 6 neurosurgeons (two board-certified neurosurgeons, two chief-residents, and two residents) described the operative procedure envisaged on 9 surgical cases of increasing surgical complexity. In details, we analyzed one surgical case described by one expert. Moreover, we measured the number of conflicts and controls reported by each surgeons. Results: Two experts were the only ones for which the report of conflicts increased with surgical complexity (respectively $75 \%$ and $73 \%$ of the conflict variance predicted by complexity). The two experts significantly activated a higher proportion of knowledge-based control (resp. 43\% and 38\%) than intermediates and residents. The residents significantly activated more motor-skill based controls (resp. $40 \%$ and $44 \%$ ) than intermediates and experts. Conclusion: It seems that expert surgical decision-making to cope with task demands is significantly associated with conflict monitoring. Knowledge-based control to regulate conflict is privileged by experts. Application: conflicts and controls analyzed through verbal reports can be used as relevant indicators to highlight critical moments in decision-making potentially requiring assistance from information systems. 


\section{INTRODUCTION}

For a long time, medical decision-making was envisaged through psychological models based on a normative approach involving an optimal solution and biases studied in laboratories (Abernathy \& Ham, 1995; Elstein \& Schwarz, 2002). Today, the Natural Decision Making (NDM) framework envisaged medical decision-making as included in a natural setting (Patel et al., 2002; Klein \& Zambok, 1997). Surgery particularly satisfies the criteria defining naturalistic decision making, i.e. ill-structured problems, uncertain dynamic environment, competing goals, action/feedback loop, time stress, high stakes, multiple operators and organisational norms (Farrington-Darby \& Wilson, 2006). NDM researches showed that to cope with these constraints, planning constitutes an important step. The detection of a problem at an early stage improves timely and effective regulation (Klein et al., 2005). During the planning stage in the aviation domain, flight pilots anticipated the potential risks and regulations which needed to be activated to keep control of the process (Amalberti \& Deblon, 1992). In the medical domain, Xiao et al. (1997) showed that anaesthetists planned some Points For Consideration (PFCs). These PFCs led to activating knowledge and using rules that enable to regulate the problem, to prepare action and to configure material assistance.

Some evidence suggests that experts are particularly able to foresee potential failures or risks and to envisage their regulation. Experts would be particularly able to mentally simulate how a situation will develop, and see antecedents and consequences of the course of action (Endsley, 1995; Hoc \& Amalberti, 2007; Hutton \& Klein, 1999). During an experimental simulation of work situation, Randel and Pugh (1996) showed that contrary to novices, expert electronic warfare technicians formed complex models of potential situations and saw potential conflicts of rules driving their activity. Flin et al. (2007) interviewed 
surgeons on their assessment of a situation and their decision on how to cope with it. They concluded that situation assessment and switching between decision methods to cope with potential problems depends on the level of surgical expertise and task demands.

One fundamental issue posed by these studies concerns the operational definition of detected problems that (potentially) interfere with activity. More precisely, concerning surgical decision-making, the question is how a problem can be concretely defined and tracked in the surgeon's decision-making process?

Cognitive Engineering can help us to answer to this question. The Cognitive Engineering framework underlines that work system is fundamentally a functional entity that controls a domain of work (Rasmussen, 1986; Vicente, 1999). In their work system, the anaesthetists mainly perform a supervision task requiring the monitoring of a set of biological parameters (Gaba, 2000; Seagull \& Sanderson, 2001). In this scope, it is relevant to define potential problems as points requiring attentional resources (Points For Consideration) during the monitoring task (Xiao et al., 1997). But in surgery work systems, surgeons rather perform a concrete intervention on the patient body, modifying it with irreversible transformations (Darzi \& Mackay, 2006). Even though the patient body is a domain requiring surgical control, the intervention process (for instance in neurosurgery, to remove a tumor, to clip an aneurism) is inherently in conflict with the laws governing the patient body (e.g. body integrity, tissues maintained in life, stable physiological balances), which are based on self-regulatory processes maintaining the biological stability of the internal environment (Lind, 2003; Miller, 2004). The notion of conflict had already been used to describe problems in surgery emerging from contradictory goals (Cook \& Woods, 1994; Young et al., 2007). More generally, Hettinger et al. (1998) proposed to consider the surgical work system as a strike environment. Thus, we will define a conflict in surgery as a problem involving a contradiction between the 
purposes and resources engaged by surgical work system, and work domain constituted by the patient body, its biological states, functions, structures, and properties. ${ }^{1}$

During an intervention, the surgical work system must maintain the control of the work domain, and so, must regulate the conflict that can be potentially envisaged or suddenly emerged in the operation room. Cognitive control allows the regulation of conflict (Botvinick et al., 2001). In Cognitive Engineering, the SRK model of cognitive control proposed by Rasmussen (1986) differentiates three control levels.

- Skill-based behaviour involves a control based on the sensory-motor loop.

- Rule-based behaviour involves a control based on rules constructed from previous experiences and giving the conditions in which an operation can be performed.

- Knowledge-based behaviour involves a control based on a conceptual model allowing an analysis of the environment and purposes to attain.

Rasmussen (1986) suggested that when confronted with a problem, an expert operator who is initially situated at the skill level of cognitive control would migrate to knowledgebased control. The latter level of control implies higher cognitive processes to understand the situation and to cope with its higher demands. But, this hypothesis was validated neither in surgery nor in other domains.

The objective of this study was firstly to evaluate the possibility of building indicators to elicit surgical conflicts and their controls from verbal protocols of surgeons during practice of pre-operative neurosurgical planning. We also wished to provide first results on the possible impact of surgical expertise on conflicts and controls along with surgical case complexity. Our final purpose is to tackle cognitive indicators of decisionmaking, representing critical moments requiring assistance from information systems.

1 Note that conflict can appear from contradictions inside the surgical work system, between the work system purposes and work system resources, for instance, if equipment does not work. This kind of conflict was not observed in the descriptions of pre-operative planning procedures. 


\section{METHOD}

\section{Participants}

We asked 6 neurosurgeons ( 5 men, 1 woman; 34.5 years old \pm 7.5 ) to describe the procedure they would adopt to operate on 9 neurosurgical cases with increasing surgical complexity.

\section{Variables and procedure}

The surgeons had different levels of expertise in neurosurgery and included: two residents (two years of residency), two intermediates (chief-residents), and two experts (board-certified neurosurgeons) from the same academic neurosurgical department. One of the expert neurosurgeons was considered as a referent. As a first step, he selected 9 surgical cases he had personally operated more than one year before the study. He classified these cases according to two criteria of surgical complexity: the anatomical location and the histopathology of the lesion (Table 1). For each case, he provided a file including clinical data (i.e. sex, age, hemispheric dominance, antecedents, history and symptoms), anatomical location and histopathology of the lesion, and relevant neuroimaging data (CT scan and MR images). A post-hoc classification of these clinical cases by another expert (board-certified neurosurgeon), following the same procedure validated the first ordering.

The 6 surgeons were asked to detail how they would go about the 9 surgical cases as in preoperative planning. The different stages of the session were as follows: (i) Study of the clinical case: the neurosurgeon examined the patient file. (ii) Verbal report of the surgical procedure: the neurosurgeons described the procedure that they would plan to remove the lesion. No time limitation was imposed during the session. The interviewer made no intervention interfering with the verbal report. The surgeon was placed in front of a microphone and a computer, which automatically recorded the verbal report. Each surgeon 
did not process more than three clinical cases per day. The order of processing followed the degree of case complexity from lower to higher in order to insure a gentle progression in difficulty for residents. None of the participants, including the referent expert, had prior information about the theoretical premises of the study and the way in which verbal protocol would be processed. Finally, verbal fluency was measured to assess its impact on the number of cognitive items extracted.

\section{Measurement}

Linguistic units representing conflicts and cognitive controls were extracted from each verbal report describing the surgical procedure stage. A conflict was negatively referred as an assertion that was not a pure description of the surgical procedure. Positively, a conflict involved an explicit or implicit contradiction between the surgical work system and work domain. Explicit conflict corresponded to linguistic formulations about a problem, worry, or difficulty that the surgeon would have to cope with, like "There will be a difficult portion..." . But sometimes, surgeons directly reported a control from which an underlying conflict could be inferred, like from the following skill-based control: "I perform the craniotomy and I am careful not to open the frontal sinus..." . In this example, the conflict was "craniotomy versus presence of frontal sinus". Implicit conflicts were then explicitly formulated by the analysts to check that it had not been already coded. A cognitive control was defined as a regulation process aimed at solving the conflict. Our coding of cognitive controls followed an extended version of the SRK approach in which we distinguished five levels of control. Skill (S) based control was coded as the implementation of a perceptual or motor process respectively divided into Perceptual Skill (Sp) and Motor Skill (Sm) based controls (Sp: "Careful not to extend the dissection to far behind"; Sm: "I dissect..."). Rule (R) based control corresponded to a conditional control of the conflict (e.g. "While I am working inside the tumor, bah.... I 
am relatively safe." or "After performing the craniotomy, I polish the bone edges if there is somme bleeding at this level".). If some conditions are satisfied, then an operation can be done. This operation can be a skill, knowledge or use of assistance. To avoid a non mastered recursion, we coded only a rule and not its components. Knowledge $(K)$ based control referred to concepts or reasoning relying on a deep understanding of the conflict foundations (e.g. "If we damage the mix nerves, swallowing disorders could occur postoperatively."). Assistance (A) based control involved the use of external resources for conflict regulation, such as patient images or surgical staff advice (e.g. "to give some steroids to the patient to decrease intracranial pressure”.). Several controls and several control levels can be activated for a single conflict. Below, we present an extract of data coding. Verbalizations were embedded in tags (in bold font, $<$... $>$ data $</ . . .>$ ) describing the nature of the data (non-conflict, conflict and content of the conflict, SRK\&A cognitive controls). It concerns a part of the exeresis phase explained by Resident 1 for the folder 10:

$<$ non-conflict $>$ Also up, take a cleavage $<$ /non-conflict $><$ C5 control Sm $>$ and move well $</$ C5 control $><$ C5 conflict "excision versus tissues around" $>$ around the tumor once $</$ C5 conflict $><$ C6 control $1 \mathrm{Sm}>$ Do not rely too much $</$ C6 control $1><$ C6 conflict: excision versus presence of left temporal lobe $>$ on the left temporal lobe, $</ \mathbf{C 6}$ conflict $><\mathbf{C 6}$ control $2 \mathrm{~K}>$ because this patient is right, to avoid language disorders $</ \mathbf{C 6}$ control $2>$

In a first stage, two clinical cases (i.e. twelve verbal reports) randomly chosen were independently coded by two analysts. Inter-rater agreement was moderate for conflicts (Cohen-Kappa test, $\mathrm{K}=0.43)$, and excellent for cognitive controls $(\mathrm{K}=0.83)$. To compensate for moderate agreement on conflict coding, all the clinical cases were coded jointly by two analysts. Disagreements about items were discussed and solved. The two analysts had backgrounds in cognitive psychology and verbal data coding. They had been trained in neurosurgery during one and half year through the reading of documents in neuroanatomy, 
multiple observations in operative rooms, and interviews and debriefings with an expert neurosurgeon (the referent expert).

\section{Statistical Methods}

Note that before quantitative analysis of data, we described the qualitative analysis of a verbalization made by an expert about a simple surgical case (folder 2). The presentation of the content of non-conflict, conflicts and cognitive control should permit to understand clearly how conflict and control can be inserted in the course of the description of surgical procedure. Due to our small participant sample, effect of expertise on cognitive items (number of conflicts, controls, distinct control levels per conflict) and verbal fluency (number of words) was assessed through a non-parametric analysis of variance (Kruskall-Wallis test).

Correlations between these variables and surgical complexity were assessed with a nonparametric rank correlation test (Tau-b of Kendall). Individual stepwise linear regression was used to measure the contribution of verbal fluency and surgical complexity to the variability of cognitive items. We added the number of conflicts per case in the regression model in order to predict the number of cognitive controls mentioned. It was assumed in our regression models that the nine case files followed an interval scale representing degrees in surgical complexity. Distribution of control level frequencies was evaluated using the chi-square test and 95\% Confidence Intervals (CI).

\section{RESULTS}

\section{Qualitative Analyses}

Table 2 presents the semantic content of non-conflictual and conflictual items found in the surgical procedure described by Expert 2 for the surgical case $n^{\circ} 2$. This verbal protocol involved conflicts with all the kinds of cognitive control that we differentiated ( $\mathrm{Sm}, \mathrm{Sp}, \mathrm{R}, \mathrm{K}$, 
\& A based control). We noticed that the order of items followed the surgical stages of the procedure. The first nine items were non-conflictual descriptions of the procedure. The first two items concerned the preparation phase: location of the tumor and context of work selected by the surgeon (intervention without neuronavigation system). Items $n^{\circ} 3$ to $n^{\circ} 9$ represented the main surgical stages required until the detachment of the scalp. A first conflictual item appeared within the detachment of the scalp (item 10). A control of the surgeon's motor skill was required to preserve the sub-temporal muscle inserted under the scalp. Item $n^{\circ} 11$ concerned access to the lesion that was potentially in conflict with the presence of cerebral arteries to preserve. This situation required a set of regulating controls: a small cortectomie on the cortical surface (Sm), a perceptual exploration to find the lesion indepth (Sp), and perceptual control of the presence of brain arteries (Sp). Items $n^{\circ} 12$ and $n^{\circ} 13$ described potential conflicts during the exeresis, involving respectively decision concerning the range of the excision in comparison with the volume of the tumor, and evaluation of the excision completeness. The choice of the range of excision involved the choice between two instruments (Rule), the use of bipolar forceps (A) and the non-use of microscope (A). The surgeon decided to realise an enlarged exeresis to insure that no tumoral tissues would be forgotten $(\mathrm{Sm})$. Evaluation of the excision was in conflict with the fact that the lesion in depth was difficult to perceive. To control the complete excision in depth, the surgeon proposed to use the microscope (A), and to check the excision (Sp) on the base of the perception of normal brain tissues (Sp). This complete excision also required to respect anterior arteries and their branches $(\mathrm{Sp})$. Item $\mathrm{n}^{\circ} 14$ involved the hemostasis stage that had to cope with the nature of the lesion which was possibly hemorrhagic. This conflict was controlled by a motor skill promoting a careful hemostasis, and knowledge on the relationship between the nature of the lesion and its properties. Item $n^{\circ} 15$ referred to a conflict potentially appearing during the dura mater closure as regards the state of the dura mater, and requiring a closure as tight as 
possible (Sm). Items 16 to 19 corresponded to non-conflictual stages ending the surgical procedure.

The emergence of surgical conflicts allowed for higlighting the critical stages envisaged by this neurosurgeon during his planning of this surgical case. These critical stages were caused by the detection of anatomical obstacles in the surgical procedure (muscles, arteries, cortical tissue above the tumor), of difficulties to discriminate the tumoral tissues from healthy tissues, of difficulty to perceive tissues in depth, and of the state of anatomical tissues (lesion and dura mater). Moreover, we noticed that the two conflicts about amplitude and completness of the excision, engaged multiple and various controls, involving motor skill precision, perceptual attention, and alternatives between instruments that will be specified during the operation, neurophysiological knowledge and choice of instruments. Several levels of control seemed required to cope with the situation.

\section{Quantitative Analyses}

Firstly, we noticed an overall effect of expertise on the number of conflicts (KruskallWallis test, $\mathrm{H}=32.2, \mathrm{p}<0.001)$, number of controls $(\mathrm{H}=33.5, \mathrm{p}<0.001)$, and number of distinct control levels per conflict $(\mathrm{H}=18.9, \mathrm{p}<0.001)$. A similar pattern of result was found for verbal fluency $(H=31.7, p<0.001)$. Pairewise comparisons showed that intermediates were those reporting the highest number of conflicts and controls and were the most fluent, followed by experts and residents (table 3). No significant difference was found between intermediates and experts in the report of control levels per conflict. We noticed that correlations between complexity and verbal fluency for the two experts and Intermediate 2 narrowly missed conventional significance levels (for the two experts, Tau-b=0.50, $\mathrm{p}=0.06$; for Intermediate 1 , Tau- $b=-0.50, p=0.06)$. It means a possible confounding effect of verbal fluency with surgical complexity. 
Individual stepwise regression analysis with surgical complexity and verbal fluency as predictors were presented in Table 4. Regression models with surgical complexity as single factor represented respectively $75 \%$ and $73 \%$ of the variance in number of conflicts reported by the two experts (Expert R: adjusted $\mathrm{R}^{2}=0.75, \mathrm{X}=0.89, \mathrm{t}=5.05, \mathrm{p}=0.01$; Expert 2: adjusted $\left.\mathrm{R}^{2}=0.73, \mathrm{X}=0.88, \mathrm{t}=4.80, \mathrm{p}=0.02\right)$. The number of conflicts significantly increased with surgical complexity for experts (Figure 1). Conflict was added as a predictor for cognitive control and control levels (Table 4). We only noticed a significant decrease in the number of control levels activated with surgical complexity for Intermediate 1 (adjusted $R^{2}=0.46, X=-$ $0.72, \mathrm{t}=-2.77, \mathrm{p}=0.03)$.

Table 5 shows the proportions of Skill-Rule-Knowledge and Assistance based controls activated by each participant according to the expertise level. The experts activated a higher proportion of knowledge-based control to regulate conflicts $(40.2 \%, \mathrm{CI}=38.2 \%-42.2 \%)$, as compared to intermediates $(30.3 \%, \mathrm{CI}=28.9 \%-31.7 \%)$ and residents $(23.3 \%, \mathrm{CI}=17 \%-29.6 \%)$. The two resident surgeons significantly activated a higher proportion of motor skills to regulate conflicts $(41.1 \%, \mathrm{CI}=33.9 \%-48.3 \%)$, than intermediates $(27.8 \%, \mathrm{CI}=25.1 \%-30.5 \%)$ and experts $(25.3 \%, \mathrm{CI}=21.8 \%-28.8 \%)$. Intra-group comparisons of global cognitive control distribution showed significant differences between Resident 1 and Resident $2\left(\mathrm{Chi}^{2}=18.4\right.$, $\mathrm{df}=4, \mathrm{p}<0.01)$ and between the two intermediates $\left(\mathrm{Chi}^{2}=29.3, \mathrm{df}=4, \mathrm{p}<0.001\right)$ but not for the experts $\left(\mathrm{Chi}^{2}=5.6, \mathrm{df}=4, \mathrm{p}>0.20\right)$.

\section{DISCUSSION}

The qualitative analysis of one surgical case envisaged by a surgeon showed us that it was possible to extract critical stages among pre-operative planning procedure. Theses critical stages involves conflicts that must be anticipated and elucidated by the surgeons to insure an activity maintained in the boundaries of safety and acceptable performance (Rasmussen, 1997). Various controls were sometimes activated to cope with a surgical conflict. They 
referred to sensory-motor and cognitive abilities, but also the well management of assistance, like the relevant use of surgical instruments. These controls correspond to solutions found by the surgeons among the resources of their work system to cope with the situation. Conflicts and controls depend on the specific nature of the surgical case, but also on its complexity and competencies of the surgeon. Quantitative analyses of our study sustained this idea. Whereas intermediates reported the largest number of conflicts, we observed that only the two experts reported more conflicts with surgical complexity. To regulate conflicts, the two experts significantly activated a larger proportion of knowledge-based control, than intermediates and residents, though residents significantly activated a larger proportion of motor-skill based controls than intermediates and experts. With the increase of surgical complexity, we noted that one intermediate reduced the number of levels of control to cope with conflicts.

We must underline that these results must taken with caution because of a set of limitative factors: the sample size, the fact that surgeons come from the same neurosurgical department, the inclusion in the sample of a referent expert who selected and classified the surgical cases. Notwithstanding, the large number of cases allowed us to carry out a quantitative analysis of verbal protocols through individual linear regression models to analyze the variance contribution of various factors. Notably, we controlled the impact of verbal fluency as a confounding predictor on results. Its measurement made it possible to take into account the possible verbal "over-investment" of participants implicitly thinking that the size of their report would be considered as a performance indicator. Moreover, the measure of the referent expert's performance and its comparison with another expert's allows us to highlight the consistency of pre-operative planning activity for experts. Even though the referent expert has more knowledge on clinical cases than the second expert, both were equally sensitive to the increase of potential conflicts with surgical case complexity and privileged knowledge-based control. 
This approach of conflict and control confirmed findings obtained through other indicators present in the literature. We found that intermediates were those producing the largest number of conflicts and controls. These results can be explained by the "intermediate effect". Research in the medical domain showed that intermediates elicit considerable amount of information during information recall, diagnosis or decision-making (Patel et al., 2000). The fact that we found no significant correlation between intermediates' conflicts and surgical complexity supports the idea that the "intermediate effect" is effectively based on an irrelevant search for hypotheses (Patel et al., 1994). Only the two experts attuned their situation assessment during planning to the task demands through an increase of conflict detection with surgical complexity (Flin et al., 2007). Moreover and in accordance with Rasmussen (1986), experts privileged knowledge-based control. In our analysis, knowledgebased control of behaviour regulates conflict and as such does not constitute an inert knowledge (Cook \& Woods, 1994). Knowledge-based control allows experts to have an indepth understanding of the conflict content (deep reasoning, Patel et al., 1994), whilst the two residents privilege a straightforward regulation through motor actions to cope with difficulty (shallow reasoning). Finally, the decrease in the number of control levels for one intermediate can be explained as a consequence of an increase in mental workload. But, of course, no conclusion can be reached with a result found only for one surgeon.

In the future, we plan to refine several parameters of our experimental design. We need a more accurate measurement of surgical complexity to pinpoint the conditions in which conflicts arise. The qualitative content of conflict and control must be systematically analyzed to apprehend surgical performance and differences among surgeons. The first qualitative analysis shows that it is possible to track how surgeons are able to detect potential conflict and find resources in their work system resources to cope with them. It represents relevant information to define the modalities of assistance coming from information systems in the 
scope of medical education and ergonomics of imagery-guided systems. The definition of neurosurgical information requirements would also benefit from the comparison of conflict and control reported both in pre-operative and intra-operative conditions. Frequently, unanticipated surgical events occur in the operative theatre. Wiegman et al. (2007) showed that disruptions in surgical flow were correlated with surgical error. An articulation between observation of disruptions (Healey et al., in press), and report of conflicts could represent an interesting development in future research.

\section{Acknowledgments}

This research was supported by Maison des Sciences de l'Homme de Bretagne (MSHB).

\section{References}

Abernathy C. M. \& Hamm R. M. (1995). Surgical intuition. Philadelphia: Hanley \& Belfus.

Amalberti, R., \& Deblon, F. (1992). Cognitive modelling of fighter aircraft process control: A step toward an intelligent onboard assistance system. International Journal of Man-Machine Studies, 36, 637-671.

Botvinick, M.M., Carter, C.S, Braver, T.S., Barch, D.M., \& Cohen, J.D. (2001). Conflict monitoring and cognitive control. Psychological Review, 108, 624-652.

Cook, R.I., \& Woods, D.D. (1994). Operating at the sharp end: the complexity of human error. In: M.S. Bogner, ed. Human Error in Medicine. Mahwah, NJ: Erlbaum, 1994.

Darzi, A. \& Mackay, S. (2006). Assessment of surgical competence. Quality in Health Care, 10, 64-69.

Elstein, AS, \& Schwarz, A. (2002). Clinical problem solving and diagnostic decision making: selective review of the cognitive literature. British Medical Journal, 324, 729-732.

Endsley, M. (1995). Toward a Theory of Situation Awareness in Dynamic Systems. Human Factors, 37, 32-64.

Farrington-Darby, T., \& Wilson, J.R. (2006). The nature of expertise: A review. Applied Ergonomics, 37, 17-32.

Fernandez-Duque, D., Baird, J;A., \& Posner, M.I. (2000). Executive attention and metacognitive regulation. Consciousness and Cognition, 9, 288-307.

Fitts P.M., \& Posner M.I. (1967). Human Performance. Belmont, CA: Brooks/Cole. 
Flin, R, Youngson, G., \& Yule, S. (2007). How do surgeons make intraoperative decision? Qual. and Saf. Health Care, 16, 235-39.

Gaba, D. M. (2000). Anaesthesiology as a model for patient safety in health care. British Medical Journal, 320, 785-788

Healey, A.N., Olsen, S., Davis, R., \& Vincent, C.A. (in press). A method for measuring work interference in surgical teams. Cognition, Technology, and Work.

Hettinger, L.J., Tannen, R.S., Geiselman, E.E., Brickman, B.J., Moroney, B.W. (1998). Surgical strike: interface design across task domains. Fourth Symposium on Human Interaction with Complex Systems, 131-142.

Hoc, J.M., \& Amalberti R. (2007). Cognitive control dynamics for reaching a satisficing performance in complex dynamic situations. Journal of Cognitive Engineering and Decision Making, 1, 1, 22-55

Hutton, R.J.B., \& Klein G. (1999). Expert decision making. Systems Engineering, 2, 1, 32-45.

Klein, G., Pliske R., Crandall B., \& Woods, D.D. (2005). Problem detection. Cognition, Technology, \& Work, 7, 14-28.

Klein, G., \& Zsambok, C. E. (1997). Natural Decision Making. Mahwah, NJ: Lawrence Erlbaum.

Lind, M. (2003). Making sense of the abstraction hierarchy in the power plant domain. Cognition, Technology, and Work, 5, 67-81.

Miller, A. (2004). A work domain analysis framework for modelling intensive care unit patients. Cognition, Technology, and Work, 6, 207-222.

Patel, V.L., Arocha, J.F., \& Kaufman, D.R. (1994). Diagnostic reasoning and medical expertise. In: D.L. Medin, ed. The Psychology of learning and motivation: advances in research and theory. Orlando, Fla: Academic Press

Patel, V.L., Glaser, R., \& Arocha, J.F. (2000). Cognition and expertise: acquisition of medical competence. Clin. Invest. Med, 23, 4, 256-260.

Patel, V.L., Kaufman, D.R., \& Arocha, J.F. (2002). Emerging paradigms of cognition in medical decision-making. Journal of Biomedical Informatics, 35, 52-75.

Randel, J.M., \& Pugh, H.L. (1996). Differences in expert and novice situation awareness in naturalistic decision making. International Journal of Human-Computer Studies, 45, 579-597.

Rasmussen, J. (1986). Information processing and human-machine interaction. An approach to cognitive engineering. NY: North-Holland.

Rasmussen, J. (1997). Risk management in a dynamic society: a modelling problem. Safety Science, 27, 183-213. 
Seagull, F. J., \& Sanderson, P. M. (2001). Anesthesia alarms in context: An observational study. Human Factors, 43, 66-78.

Vicente, K. J. (1999). Cognitive Work Analysis, toward safe, productive and healthy computer-based work. Mahwah, NJ: Erlbaum.

Wiegmann D.A, ElBardissi, A.W., Dearani J.A., Daly R.C, Sundt T.M. (2007). Disruptions in surgical flow and their relationship to surgical errors: An exploratory investigation. Surgery, $142,5,658-665$.

Xiao, Y., Milgram, P., \& Doyle, D.J. (1997). Planning behaviour and its functional role in interactions with complex systems. IEEE Transactions on systems, man, and cybernetics Part A: Systems and Humans, 27, 313-324.

Young, J.S., Smith, R.L., Guerlain, S., \& Nolley, B. (2007). How residents think and make medical decisions: implications for education and patient safety. The American Surgeon, 73, 548-554.

\section{AUTHORS}

Thierry Morineau is a cognitive psychology and ergonomics researcher at the University of Southern Brittany. He received his Ph.D. in cognitive psychology from the University of Angers in 1996.

Xavier Morandi is full professor of anatomy at the University of Rennes 1 and neurosurgeon at the Neurosurgical Department of the Pontchaillou University Hospital, Rennes. He obtained his MSc in biological imaging in 1996 and supervises Ph.D. students since 2003.

Nadège Le Moëllic received a Master in Ergonomics and Communication Science in 2007. She is presently a Ph.D. student in cognitive psychology at the University of Southern Brittany.

Sylma Diabira is a medical doctor, specialising in neurosurgery. He received is M.D. degree in October 2005 and neurosurgical board in November 2005 from the school of medicine in Angers. He was a research scholar between October 2001 and October 2003 at the University of Miami (molecular biology in the glioma).

Laurent Riffaud is neurosurgeon at the Pontchaillou University Hospital, Rennes. He finished residency in 2000 and is now involved in paediatric neurosurgery.

Claire Haegelen is neurosurgeon and anatomist at the the Pontchaillou University Hospital, Rennes. She received her Ph.D. in neurosurgery from the University of Rennes in 2006.

Pierre-Louis Hénaux is resident in Neurosurgery at the Pontchaillou University Hospital, Rennes.

Pierre Jannin is a senior INSERM researcher at the University of Rennes. In 1988, he received his Ph.D degree in multimodal 3D imaging for neurosurgery. He was awarded the Habilitation in 2005 on Information guided Surgery. 

TABLE 1: Summary of clinical cases classified according to the increasing order of complexity

\begin{tabular}{|c|c|c|}
\hline$N^{\circ}$ file & Critical data and location & Histopathology \\
\hline File $\mathrm{N}^{\circ} 1$ & $\begin{array}{l}\text { A } 48 \text { year-old man, right-handed, } 2 \text { generalized } \\
\text { seizures, normal clinical examination } \\
\text { Right middle frontal gyrus }\end{array}$ & Cavernoma \\
\hline File $\mathrm{N}^{\circ} 2$ & $\begin{array}{l}\text { A } 65 \text { year-old man, right-handed, headaches and mild } \\
\text { aphasia for one month } \\
\text { Left superior frontal gyrus }\end{array}$ & Glial tumor \\
\hline File $N^{\circ} 3$ & $\begin{array}{l}\text { A } 20 \text { year-old man, right-handed, left hemiparesia for } \\
6 \text { weeks, headaches and bradypsychia } \\
\text { Right fronto-temporal insular area }\end{array}$ & Glial tumor \\
\hline File $N^{\circ} 4$ & $\begin{array}{l}\text { A } 53 \text { year-old woman, right-handed, weakness in her } \\
\text { right lower limb when walking } \\
\text { Left fronto temporal insular convexity }\end{array}$ & Meningioma \\
\hline File $N^{\circ} 5$ & $\begin{array}{l}\text { A } 33 \text { year-old woman, right-handed, headaches. Left } \\
\text { fronto temporal insular area }\end{array}$ & Glial tumor \\
\hline File $N^{\circ} 6$ & $\begin{array}{l}\text { A } 57 \text { year-old woman, right-handed, trigeminal } \\
\text { neuralgia involving the left mandibular and maxillary } \\
\text { nerves } \\
\text { Left cavernous sinus and tentorial incisura }\end{array}$ & Meningioma \\
\hline File $N^{\circ} 7$ & $\begin{array}{l}\text { A } 16 \text { year old boy, right-handed, headaches, insipid } \\
\text { diabetes and bitemporal hemianopsia. Suprasellar } \\
\text { area }\end{array}$ & Craniopharyngioma \\
\hline File $N^{\circ} 8$ & $\begin{array}{l}\text { A } 35 \text { year-old woman, right deafness and vestibular } \\
\text { syndrome. } \\
\text { Right ponto-cerebellar area }\end{array}$ & $\begin{array}{c}\text { Vestibular } \\
\text { Schwannoma }\end{array}$ \\
\hline File $N^{\circ} 9$ & $\begin{array}{l}\text { A } 51 \text { year-old woman, headaches and paresthesia in } \\
\text { four limbs with pyramidal reflexes and right } \\
\text { hypoglossal nerve palsy. } \\
\text { Anterior part of the foramen magnum }\end{array}$ & $\begin{array}{l}\text { Meningioma of the } \\
\text { foramen magnum }\end{array}$ \\
\hline
\end{tabular}


TABLE 2: Conflicts, controls and non-conflictual items coded from folder $n^{\circ} 2$, Expert 2 (Sm : motor skill; Sp: perceptual skill; R: rule; K: knowledge; A: assistance)

\begin{tabular}{|c|c|c|c|}
\hline Item & Non-conflict & $\begin{array}{l}\text { Conflict :Surgical work } \\
\text { system/Work domain }\end{array}$ & Control of conflict \\
\hline 1 & Location of the tumor & & \\
\hline 2 & $\begin{array}{l}\text { Do not use the } \\
\text { neuronavigation system }\end{array}$ & & \\
\hline 3 & $\begin{array}{l}\text { Suggests a slightly enlarged } \\
\text { excision }\end{array}$ & & \\
\hline 4 & $\begin{array}{l}\text { Installation of the patient, } \\
\text { type of head board }\end{array}$ & & \\
\hline 5 & Incision & & \\
\hline 6 & Shaving of the scalp & & \\
\hline 7 & $\begin{array}{l}\text { Form and amplitude of the } \\
\text { incision }\end{array}$ & & \\
\hline 8 & $\begin{array}{l}\text { Preparation of the operative } \\
\text { field (Betadine, infiltration) }\end{array}$ & & \\
\hline 9 & Detachment of the scalp & & \\
\hline 10 & & $\begin{array}{l}\text { Detachment of the scalp/ Insertion } \\
\text { of sub-temporal muscle }\end{array}$ & Sm(respect of sub-temporal muscle) \\
\hline 11 & & $\begin{array}{l}\text { Access to the lesion in depth/ } \\
\text { Presence of cerebral arteries }\end{array}$ & $\begin{array}{l}\mathrm{Sm} \text { (small cortectomie on the surface) } \\
\mathrm{Sp} \text { (find in-depth lesion) } \\
\text { Sp(control of brain arteries) }\end{array}$ \\
\hline 12 & & $\begin{array}{l}\text { Range of the excision/Volume of } \\
\text { the tumor }\end{array}$ & $\begin{array}{l}\mathrm{R} \text { (excision with dissectron or sucker) } \\
\text { Sm(enlarged exeresis) } \\
\text { A(bipolar forceps) } \\
\text { A(non-use of microscope as a first } \\
\text { step) }\end{array}$ \\
\hline 13 & & $\begin{array}{l}\text { Complete excision/ Lesion in } \\
\text { depth }\end{array}$ & $\begin{array}{l}\text { A(microscope at end of procedure) } \\
\text { Sp(check of complete excision in } \\
\text { depth) } \\
\text { Sp(recover normal brain as possible) } \\
\text { Sp(well respect of previous arteries } \\
\text { and branches) }\end{array}$ \\
\hline 14 & & $\begin{array}{l}\text { Hemostasis/ Possibly hemorrhagic } \\
\text { lesion }\end{array}$ & $\begin{array}{l}\text { Sm(careful hemostasis) } \\
\text { K(injury possibly bleeding, because } \\
\text { possibly infiltrative lesion) }\end{array}$ \\
\hline 15 & & $\begin{array}{l}\text { Dura mater closing/State of dura } \\
\text { mater }\end{array}$ & $\begin{array}{l}\text { Sm(closure dura mater as tight } \\
\text { as possible) }\end{array}$ \\
\hline 16 & suspension & & \\
\hline 17 & $\begin{array}{l}\text { Osteosynthesis of } \\
\text { component bone and } \\
\text { closure }\end{array}$ & & \\
\hline 18 & Replacing the bone powder & & \\
\hline 19 & $\begin{array}{l}\text { Closure of the scalp using } \\
\text { the usual technique. }\end{array}$ & & \\
\hline
\end{tabular}


TABLE 3: Conflicts, cognitive controls, number of controls per conflict, number of levels of control per conflict, and number of words activated by each surgeon ( $n=9$ surgical cases per participant)

\begin{tabular}{|c|c|c|c|c|}
\hline \multirow[t]{2}{*}{ Participants } & \multicolumn{4}{|c|}{ Median [Min-Max] } \\
\hline & Conflict & Control & $\begin{array}{c}\text { Level of } \\
\text { Control/Conflict }\end{array}$ & Words \\
\hline Resident 1 & 7 [2-16] & 13 [3-28] & $1.5[1.1-1.8]$ & 434 [324-519] \\
\hline Resident 2 & $3[1-7]$ & $6[2-14]$ & $1.3[1.0-2.0]$ & 128 [96-182] \\
\hline Total Residents & $5.5^{\star}$ & $9.5^{\star}$ & $1.4^{*}$ & $253^{*}$ \\
\hline Intermediate 1 & 18 [13-40] & 58 [23-108] & 1.9 [1.4-2.6] & 1248 [363-1771] \\
\hline Intermediate 2 & 28 [20-34] & 65 [55-90] & $2.0[1.6-2.3]$ & 1279 [799-1570] \\
\hline $\begin{array}{l}\text { Total } \\
\text { Intermediates }\end{array}$ & $24^{*}$ & $63^{\star}$ & 2.0 & $1248.5^{\star}$ \\
\hline Expert $\mathrm{R}$ & $10[3-21]$ & 30 [6-89] & $1.7[1.0-2.2]$ & 513 [390-1119] \\
\hline Expert 2 & $10[5-27]$ & $28[14-72]$ & $1.8[1.5-2.1]$ & 443 [277-667] \\
\hline Total Experts & $10^{\star}$ & $29.5^{\star}$ & 1.8 & $490.5^{\star}$ \\
\hline
\end{tabular}

${ }^{*} z$ value for Kruskall-Wallis pairewise comparison with $p^{\times} 05$ 
TABLE 4: Individual multiple regression models for each cognitive variable measured.

Step by step evaluation of the models with $X$ values of predictor contributions.

\begin{tabular}{|c|c|c|c|c|c|c|c|c|}
\hline Variables & Participants & $\boldsymbol{R}$ & $\begin{array}{c}\text { Adjusted } \\
R^{2}\end{array}$ & $F$ & $P$ value & $\begin{array}{c}\text { Verbal } \\
\text { fluency }\end{array}$ & Complexity & Conflict \\
\hline & & & & & & $x$ & $x$ & $x$ \\
\hline \multirow[t]{6}{*}{ Conflict } & Resident 1 & 0.42 & -0.10 & 0.65 & 0.53 & & & $\mathrm{~N} / \mathrm{A}$ \\
\hline & Resident 2 & 0.65 & 0.24 & 2.23 & 0.19 & & & $\mathrm{~N} / \mathrm{A}$ \\
\hline & Intermediate 1 & 0.71 & 0.34 & 3.04 & 0.12 & & & $\mathrm{~N} / \mathrm{A}$ \\
\hline & Intermediate 2 & 0.77 & 0.54 & 10.36 & $<0.02$ & $0.77^{\star}$ & 0.56 & $N / A$ \\
\hline & Expert $\mathrm{R}$ & 0.89 & 0.75 & 25.54 & $<0.02$ & 0.52 & $0.89^{*}$ & $\mathrm{~N} / \mathrm{A}$ \\
\hline & Expert 2 & 0.88 & 0.73 & 23.05 & $<0.003$ & 0.28 & $0.88^{*}$ & $\mathrm{~N} / \mathrm{A}$ \\
\hline \multirow[t]{6}{*}{ Control } & Resident 1 & 0.92 & 0.83 & 40.42 & $<0.0001$ & -0.08 & -0.12 & $0.92^{*}$ \\
\hline & Resident 2 & 0.91 & 0.80 & 33.71 & $<0.002$ & 0.15 & 0.27 & $0.91^{*}$ \\
\hline & Intermediate 1 & 0.89 & 0.77 & 27.20 & $<0.002$ & -0.02 & -0.08 & $0.89^{*}$ \\
\hline & Intermediate 2 & 0.80 & 0.42 & 2.92 & 0.14 & & & \\
\hline & Expert R & 0.90 & 0.79 & 30.94 & $<0.002$ & $0.90^{*}$ & 0.33 & 0.37 \\
\hline & Expert 2 & 0.97 & 0.94 & 125.62 & $<0.0001$ & 0.23 & -0.03 & $0.97^{*}$ \\
\hline \multirow{6}{*}{$\begin{array}{l}\text { Control } \\
\text { level }\end{array}$} & Resident 1 & 0.63 & 0.03 & 1.07 & 0.44 & & & \\
\hline & Resident 2 & 0.46 & -0.26 & 0.45 & 0.73 & & & \\
\hline & Intermediate 1 & 0.72 & 0.46 & 7.68 & $<0.03$ & -0.24 & $-0.72^{*}$ & -0.02 \\
\hline & Intermediate 2 & 0.51 & -0.18 & 0.59 & 0.65 & & & \\
\hline & Expert $\mathrm{R}$ & 0.51 & -0.19 & 0.58 & 0.65 & & & \\
\hline & Expert 2 & 0.70 & 0.17 & 1.56 & 0.31 & & & \\
\hline
\end{tabular}

* Predictor retained in regression model for its significant contribution: $t$ test with $p<0.05$ 
TABLE 5: Global proportions of Skill-Rule-Knowledge and Assistance based controls activated by each surgeon

$\mathrm{n}$ : total number of controls and the highest total percentage found in bold type

\begin{tabular}{|c|c|c|c|c|c|c|}
\hline & Knowledge & Rule & $\begin{array}{c}\text { Perceptual } \\
\text { Skill }\end{array}$ & $\begin{array}{l}\text { Motor } \\
\text { Skill }\end{array}$ & Assistance & $\mathrm{n}$ \\
\hline Resident 1 & $30.7 \%$ & $4.3 \%$ & $14.3 \%$ & $40.0 \%$ & $10.7 \%$ & 121 \\
\hline Resident 2 & $8.5 \%$ & $18.6 \%$ & $18.6 \%$ & $44.1 \%$ & $10.2 \%$ & 59 \\
\hline Total Resident & $23.3 \%$ & $9.4 \%$ & $15.6 \%$ & $41.1 \%{ }^{*}$ & $10.6 \%$ & 180 \\
\hline Intermediate 1 & $28.9 \%$ & $10.6 \%$ & $10.2 \%$ & $29.4 \%$ & $20.9 \%$ & 385 \\
\hline Intermediate 2 & $31.2 \%$ & $17.3 \%$ & $14.2 \%$ & $26.8 \%$ & $10.5 \%$ & 641 \\
\hline Total Intermediates & $30.3 \%$ & $14.9 \%$ & $12.7 \%$ & $27.8 \%$ & $14.3 \%$ & 1026 \\
\hline Expert $\mathrm{R}$ & $43.1 \%$ & $6.6 \%$ & $21.7 \%$ & $21.0 \%$ & $7.6 \%$ & 272 \\
\hline Expert 2 & $37.7 \%$ & $6.2 \%$ & $18.7 \%$ & $29.2 \%$ & $8.2 \%$ & 305 \\
\hline Total Expert & $40.2 \%$ * & $6.4 \%$ & $20.1 \%$ & $25.3 \%$ & $8 \%$ & 577 \\
\hline
\end{tabular}

- Significant Confidence Interval non-overlap between surgeon groups, $p<0.05$ 


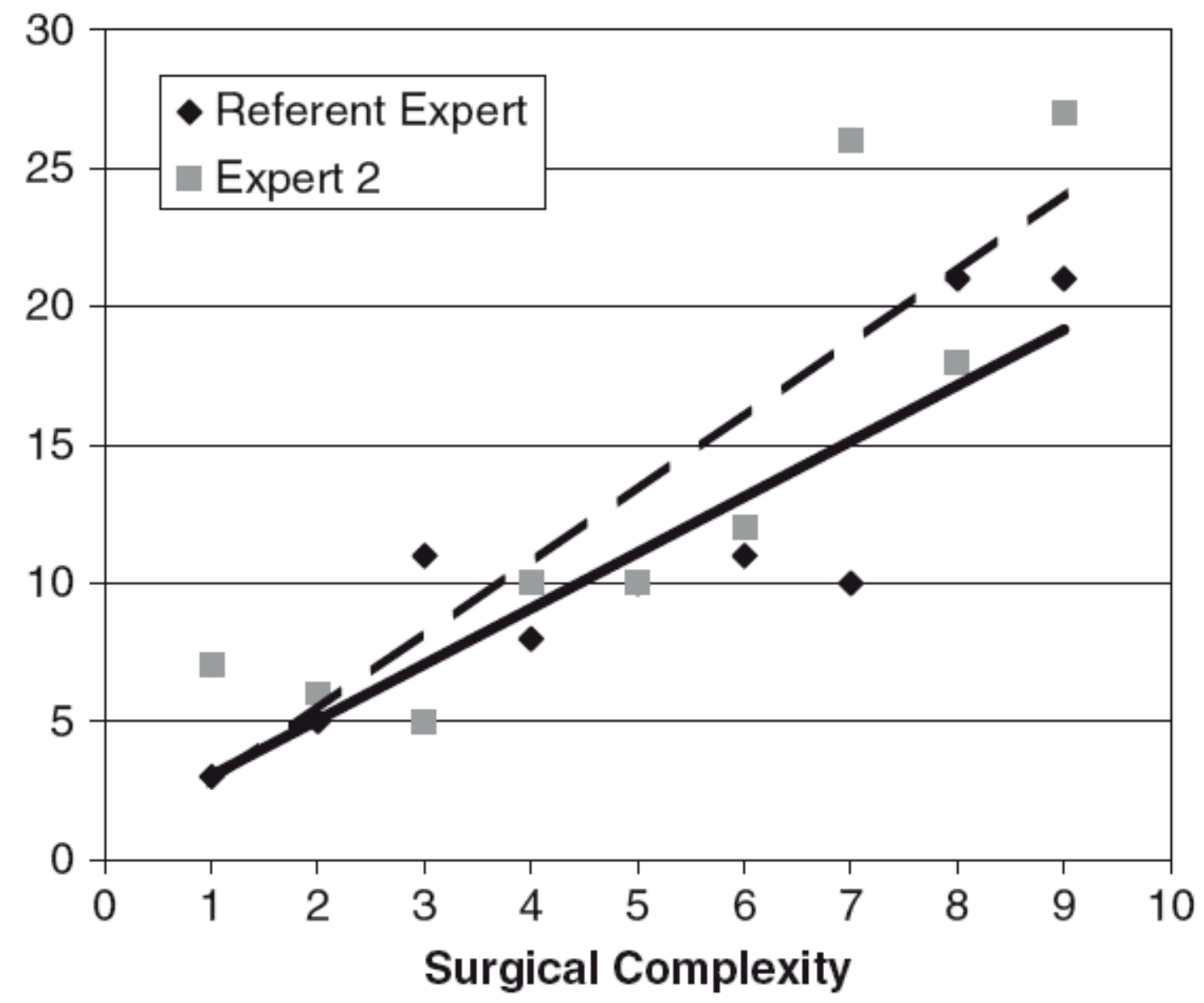

Figure 1. Number of conflicts reported by the two experts along with surgical complexity with linear trends (in dashed line, linear trend for Expert 2). 